Vol. 1 No. 1, Feb 2021, hlm. 9 - 18

DOI: https://doi.org/10.33330/.v1i1.1008

Available online at http://jurnal.stmikroyal.ac.id/index.php/jutsi

\title{
PEMANFAATAN SMARTPHONE SEBAGAI SISTEM KENDALI PADA KENDARAAN BERMOTOR BEBRBASIS MIKROKONTROLER ARDUINO UNO
}

\author{
Nurdiana Syari Nasution ${ }^{1}$, Jhonson Efendi ${ }^{2 *}$, Sudarmin $^{3}$ \\ ${ }^{1}$ Mahasiswa Prodi Teknik Komputer, STMIK Royal \\ ${ }^{2}$ Prodi Teknik Komputer, STMIK Royal \\ ${ }^{3}$ Prodi Sistem Informasi, STMIK Royal \\ Email : jhonefendi12@yahoo.co.id
}

\begin{abstract}
In this design, a remote control system will be made in the form of an Android Smartphone using Bluetooth transmission media and an Arduino Uno microcontroller. The purpose of this tool is designed to find out how an electric car controller using a Smartphone via Bluetooth communication media can work. Data collection techniques using observation (observation) and literature study (Library Research). Meanwhile, data processing techniques use the preparation of tools and materials and design of hardware and software systems. The results of this study indicate that according to the title that the author took, the use of smartphones as a control system in motorized vehicles has been successful and can be used, lights and horns can turn on and off, the car can move back and forth according to the commands received through the buttons on the application in smartphone. The control system for an electric car type motor vehicle uses the Arduino Uno Microcontroller as a controller and a processor for input data received from a Smartphone via a relay, so that it can issue output data in the form of movements from DC motors, horns and electric car lights.
\end{abstract}

Keywords : Bluetooth; Microcontroller; Motor Vehicle; Remote; Smartphone

\begin{abstract}
Abstrak: Pada rancangan ini, akan dibuat sistem kendali layaknya sebuah remote control berupa Smartphone Android menggunakan media transmisi Bluetooth dan Mikrokontroller Arduino Uno. Tujuan Alat ini dirancang yaitu untuk mengetahui bagaimana pengendali mobil listrik menggunakan Smartphone melalui media komunikasi Bluetooth ini dapat bekerja. Teknik pengumpulan data menggunakan pengamatan (observation) dan studi kepustakaan (Library Research). Sedangkan teknik pengolahan data menggunakan persiapan alat dan bahan serta perancangan sistem hardware dan software. Hasil penelitian ini menunjukkan bahwa sesuai judul yang penulis ambil, pemanfaatan smartphone sebagai sistem kendali pada kendaraan bermotor sudah berhasil dan dapat digunakan, lampu dan klakson dapat menyala dan mati, mobil dapat bergerak maju dan mundur sesuai peritah yang diterima melalui tombol yang ada pada aplikasi di smartphone. Sistem kendali kendaraan bermotor jenis mobil listrik menggunakan Mikrokontroler Arduino Uno sebagai pengendali dan pengolah data input yang diterima dari Smartphone melalui relay, sehingga dapat mengeluarkan data output berupa gerakan dari motor DC, klakson dan lampu mobil listrik.
\end{abstract}

Kata Kunci : Bluetooth; Kendaraan Bermotor; Mikrokontroler; Remote; Smartphone 
Vol. 1 No. 1, Feb 2021, hlm. 9 - 18

DOI: https://doi.org/10.33330/.v1i1.1008

Available online at http://jurnal.stmikroyal.ac.id/index.php/jutsi

\section{PENDAHULUAN}

Teknologi yang semakin maju pada saat ini membuat para pengguna semakin berupaya dalam menciptakan sesuatu yang dapat memudahkan pekerjaannya. Kemajuan teknologi pada saat ini tidak terpisahkan dari masalah otomatisasi dan telekomunikasi yang berguna dalam kehidupan sehari-hari. Otomatisasi selalu berkaitan dengan mesin yang menggantikan peran tenaga manusia, sehingga seakan-akan manusia telah dimanjakan oleh adanya alat-alat yang bersifat otomatis.

Pada zaman yang semakin modern ini, membuat para pengguna tidak dapat dipisahkan dengan Handphone sebagai alat komunikasi, terutama bagi mereka yang memiliki sosialitas tinggi. Sebelumnya Handphone diketauhi hanya digunakan sebagai media berkomunikasi jarak jauh. Tetapi, seiring perkembangannya yang sangat cepat, kemudian sekarang Handphone sudah dapat bertambah fungsi dan bukan hanya sekedar media untuk komunikasi saja. Karena dengan adanya perpaduan Pocket PC, serta perangkat digital lainnya seperti kamera digital sehingga kini Handphone sudah umum disebut Smartphone atau telepon pintar [1].

Detik.com, Jakarta - Salah satu Negara di Asia Tenggara yang terbilang cukup banyak pengguna Smartphone adalah Indonesia. Totalnya diperkirakan mencapai empat puluh satu juta pengguna dan persentasenya mencapai sembilan puluh empat persen. Salah satu alasan mengapa masyarakat Indonesia menggunakan Smartphone yang mempunyai sistem operasi Android yaitu karena pengoperasiannya mudah seperti pengoperasian komputer pada umumnya. Seperti umumnya komputer, kini Smartphonepun telah mempunyai banyak aplikasi yang bisa ditambahkan sesuai dengan keinginan [2]. Dahulu Handphone hanya menggunakan infrared atau Bluetooth untuk mengirimkan data ke sesama Handphone yang juga memiliki Bluetooth dengan batasan jarak tertentu. Tetapi kini pada Smartphone, Bluetooth sudah dapat dipadukan dengan aplikasi dan juga berfungsi sebagai media pengiriman data/file tidak hanya ke sesama perangkat smartphone tetapi juga ke perangkat kontrol secara jarak jauh dengan bantuan perangkat modul Bluetooth. Salah satu penerapannya yaitu membuat sistem kendali pada kendaraan bermotor jenis mobil listrik secara nirkabel. Mobil listrik adalah salah satu kendaraan yang menggunakan motor listrik DC. Popularitas dari mobil listrik kini semakin menjadi-jadi di era modern ini karena sebagian besar masyarakat berlomba-lomba untuk menggunakan peralatan atau alat transportasi yang ramah lingkungan. Pengemudinya juga merasa lebih nyaman karena konsrtruksi mesin pada mobil listrik lebih sederhana sehingga lebih mudah dikendarai dibandingkan dengan mobil konvensional. Selain itu tidak menimbulkan kebisingan dan asap yang menyebabkan polusi udara [3].

Pada perancangan ini akan dibuat sebuah sistem kendali yang dapat digunakan untuk menyalakan dan mematikan mesin pada mobil listrik tanpa menggunakan kunci konvensional, selain itu sistem juga dapat mengendalikan maju, mundur tanpa harus menggunakan setir secara manual, juga dapat menyalakan dan mematikan lampu tanpa menggunakan saklar manual, dan klakson mobil listrik tanpa menggunakan tombol manual, tetapi menggunakan sebuah remote berupa smartphone dan media Bluetooth yang berfungsi megirimkan data kepada MikrokontrollerArduino Uno.

Perancangan alat ini akan dibuat sistem kendali layaknya sebuah remote control berupa Smartphone Android menggunakan media transmisi Bluetooth dan 
Vol. 1 No. 1, Feb 2021, hlm. 9 - 18

DOI: https://doi.org/10.33330/.v1i1.1008

Available online at http://jurnal.stmikroyal.ac.id/index.php/jutsi

Mikrokontroller Arduino Uno. Alasan penulis menggunakan Smartphone sebagai remote dan media Bluetooth dalam perancangan ini karena menurut penulis, dibandingkan dengan kunci konvensional, Smartphone merupakan benda yang tidak pernah lepas dalam aktivitas sehari-hari dan mudah untuk dibawa kemana-mana, sehingga cocok untuk digunakan sebagai remote control mobil listrik karena dapat menggantikan peran setir, saklar lampu dan klakson yang manual. Selain itu Bluetooth juga sudah awam untuk digunakan dan tanpa menggunakan layanan internet, sehingga pengguna tidak perlu mengeluarkan biaya [4]. Tujuan dari pengadaan penelitian ini adalah untuk mengetahui dan merancang sistem pengendali kendaraan bermotor jenis mobil listrik berbasis Mikrokontroller Arduino Uno yang dikendalikan oleh Smartphone melalui media transmisi Bluetooth serta mengetahui cara kerja sistem kendali mobil listrik menggunakan Smartphone dan juga membantu para pengemudi dalam mengendalikan mobil listrik secara mudah, praktis, dan otomatis dengan memanfaatkan smartphone sebagai remote.

\section{METODE}

Dalam melaksanakan penelitian, dimana peneliti mengambil data dengan cara observasi baik secara langsung terhadap para pengguna smartphone maupun secara tidak langsung terhadap pengguna mobil listrik. Dan dilanjutkan dengan peneliti mencari referensi atau data dengan cara membaca dan mempelajari sumber-sumber yang akurat, termasuk didalamnya literature tentang penulisan dan mengenai hal-hal yang mendukung penulisan penelitian ini.

Dalam perancangan sistem kendali ini, menggunakan mobil listrik sebagai objek. Sistem kendali ini akan dipasang pada mobil listrik dengan bentuk rangkaian elektronika Arduino Uno dan komponen pendukung lainnya yang akan difungsikan untuk mengontrol mobil listrik melalui Smartphone Android [5]. Dalam perancangan ini membutuhkan 2 buah software, yaitu Arduino IDE progam untuk mengontrol hardware dan Mit App Inventor digunakan sebagai pembuatan aplikasi pada perangkat Android yaitu dengan menggunakan block code [6].

\section{HASIL DAN PEMBAHASAN}

Tujuan blok diagram ini adalah agar memudahkan penulis dalam perancangan alat yang dibuat. Blok diagram merupakan diagram dari sebuah sistem, dimana bagian utama atau fungsi utama yang diwakilkan oleh sebuah blok yang saling terhubung dengan garis, yang mana menunjukkan sebuah sistem yang bekerja mulai dari input, proses sampai dengan output.

Komponen pengolahan data atau proses yakni Mikrokontroller Arduino Uno yang akan bertindak sebagai pengolah data, data yang telah diterima oleh perangkat modul Bluetooth $\mathrm{HC}-05$ akan dikirim kedalam mikrokontroler dan diproses, dan komponen output yakni klakson, lampu, dan motor DC yang menjadi penggerak mobil listrik melalui relay 4 chanel. Adapun blok diagram dari perancangan alat kendali mobil listrik yang akan dibuat sebagai berikut: 
Vol. 1 No. 1, Feb 2021, hlm. 9 - 18

DOI: https://doi.org/10.33330/.v1i1.1008

Available online at http://jurnal.stmikroyal.ac.id/index.php/jutsi

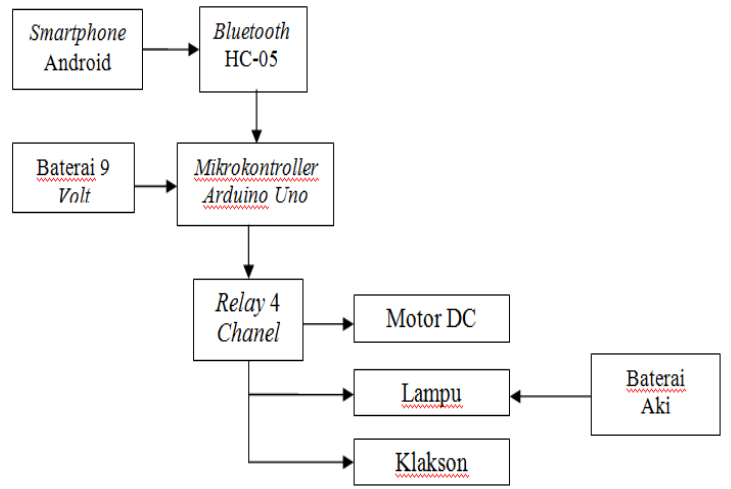

Gambar 1. Diagram Blok Sistem

Pada bab ini penulis akan membahas mengenai rangkaian pada setiap blok dan pengujian pada alat kerja dengan tujuan untuk mengetahui apakah alat yang dirancang bekerja sesuai dengan yang diinginkan serta mengetahui hasil pengukuran tegangan yang bekerja pada rangkaian saat beroperasi dan juga menetukan titik uji dari rangkaian. Setelah selesai merakit/merancang alat dengan setiap komponen-komponennya, maka selanjutnnya penulis akan melakukan pengujian pada setiap rangkaian komponen sehingga nantinya akan didapatkan hasil sesuai dengan yang diharapkan. Adapun masing-masing rangkaian yang akan diuji dan dibahas antara lain, baterai, Arduino, relay, modul Bluetooth $\mathrm{HC}-05$, dan motor DC.

Sumber tegangan atau energi pada penelitian yang dilakukan adalah menggunakan baterai aki yang mengeluarkan tegangan 12 Volt dan baterai dengan kapasitas 9 Volt. Di mana dalam penggunaanya nanti sangat cocok dengan alat yang digunakan. Mikrokontroler Arduino Uno membutuhkan supply sebesar 5 Volt - 9 Volt. Adapun pengujian sumber tegangan baterai Aki dan 9 Volt dapat dilihat pada gambar 2 :

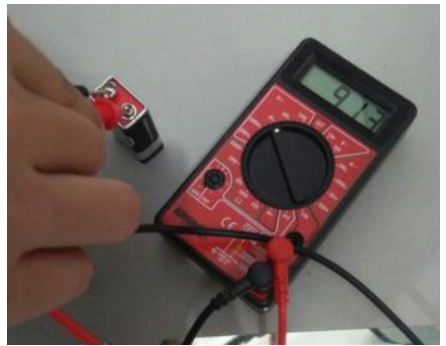

Gambar 2. Pengujian Rangkaian Baterai 9 Volt

Adapun tabel dari hasil pengujian baterai 9 volt adalah sebagai berikut:

Tabel 1. Hasil Pengujian Baterai 9 volt

\begin{tabular}{|c|c|c|c|}
\hline $\begin{array}{c}\text { Kutub } \\
\text { Positif } \\
(+)\end{array}$ & $\begin{array}{c}\text { Kutub } \\
\text { Negatif } \\
(-)\end{array}$ & Hasil & Keterangan \\
\hline Merah & Hitam & 9.13 & Baik \\
\hline Hitam & Merah & -9.13 & Baik \\
\hline
\end{tabular}


Vol. 1 No. 1, Feb 2021, hlm. 9 - 18

DOI: https://doi.org/10.33330/.v1i1.1008

Available online at http://jurnal.stmikroyal.ac.id/index.php/jutsi

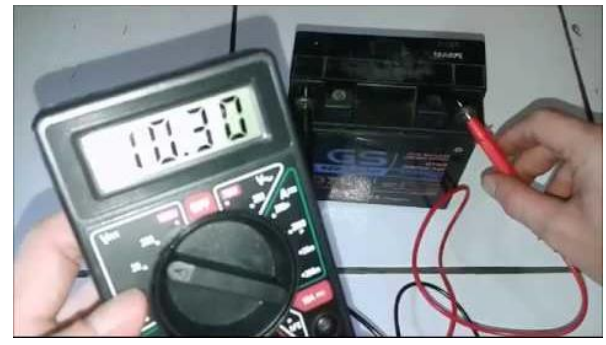

Gambar 3. Pengujian Rangkaian Baterai 9 Volt

Adapun tabel dari hasil pengujian baterai Aki adalah sebagai berikut:

Tabel 2. Hasil Pengujian Baterai Aki

\begin{tabular}{|c|c|c|c|}
\hline Kutub Positif $(+)$ & Kutub Negatif (-) & Hasil & Keterangan \\
\hline Merah & Hitam & 10.30 & Baik \\
\hline Hitam & Merah & -10.30 & Baik \\
\hline
\end{tabular}

Dalam pengujian rangkaian Arduino ini dihubungkan langsung pada sumber daya rekomendasi 7-12 VDC. Rangkaian Arduino ini sengaja diprogram untuk mengaktifkan relay dan modul bluetooth yang dihubungkan langsung pada port Arduino. Sehingga dapat dilihat rangkaian tersebut dapat bekerja dengan baik atau tidak. Pengujian rangkaian Arduino dapat dilihat pada gambar 4:

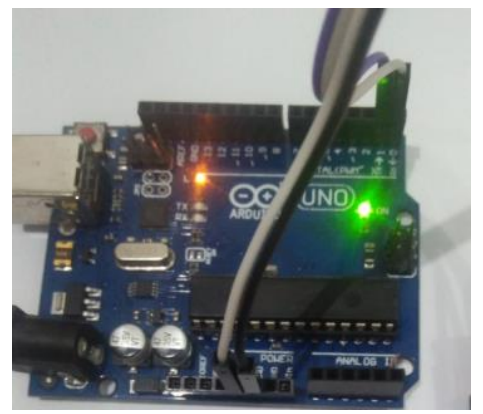

Gambar 4. Pengujian Rangkaian Arduino

Dalam pengujian modul Bluetooth HC-05 juga dihubungkan langsung dengan port 0 dan 1 Arduino dengan Pin RX dan TX pada modul bluetooth dan diberi daya 5 VDC dari port Arduino. Adapun gambar rangkaian relay yang terhubung dengan Arduino sebagai berikut:

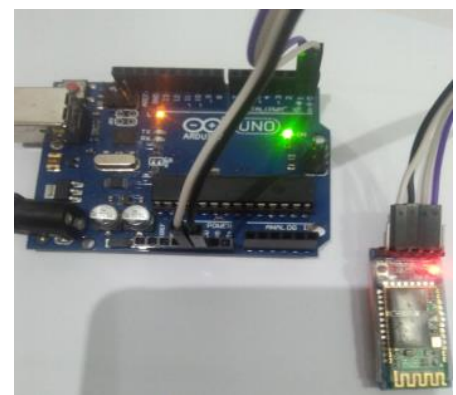

Gambar 5. Pengujian Rangkaian Bluetooth 
Vol. 1 No. 1, Feb 2021, hlm. 9 - 18

DOI: https://doi.org/10.33330/.v1i1.1008

Available online at http://jurnal.stmikroyal.ac.id/index.php/jutsi

Proses pengujian dilakukan dengan cara menghubungkan smartphone dan rangkaian alat. Untuk melakukan pengujian ini dilakukan sebanyak 15 kali untuk mengetahui proses respon yang diterima saat proses pengoneksian. Berikut hasil pengujian dari smartphone dan rangkaian alat:

Tabel 3. Hasil Pengujian Modul Bluetooth

\begin{tabular}{|c|c|c|}
\hline Pengujian ke- & Jarak & Keterangan \\
\hline 1 & 2 Meter & Terhubung \\
\hline 2 & 3 Meter & Terhubung \\
\hline 3 & 4 Meter & Terhubung \\
\hline 4 & 5 Meter & Terhubung \\
\hline 5 & 6 Meter & Terhubung \\
\hline 6 & 7 Meter & Terhubung \\
\hline 7 & 8 Meter & Terhubung \\
\hline 8 & 9 Meter & Terhubung \\
\hline 9 & 10 Meter & Terhubung \\
\hline 10 & 11 Meter & Terhubung \\
\hline 11 & 12 Meter & Terhubung \\
\hline 12 & 13 Meter & Terputus \\
\hline
\end{tabular}

Dalam pembuatan alat ini, penulis menggunakan rangkaian relay 4 chanel. Dalam pengujiannya rangkaian relay diberi daya 5 VDC dari port Arduino dan port 9, 10, 11, dan 12 pada Arduino akan dihubungkan dengan motor DC, lampu dan klakson . Dimana Arduino tersebut sudah di upload program untuk menyalakan dan mematikan relay. Sehingga ketika program yang diproses oleh Arduino berlogika 1 (satu), maka relay akan aktif dan sebaliknya ketika program yang di proses Arduino berlogika 0 (nol), maka relay akan non aktif. Adapun gambar rangkaian relay yang terhubung dengan Arduino sebagai berikut:

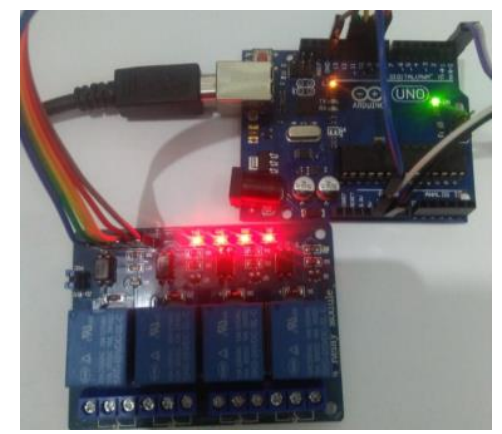

Gambar 6. Pengujian Rangkaian Relay berikut:

Adapun hasil pengujian dari aplikasi remote control terhadap relay yaitu sebagai 
Vol. 1 No. 1, Feb 2021, hlm. 9 - 18

DOI: https://doi.org/10.33330/.v1i1.1008

Available online at http://jurnal.stmikroyal.ac.id/index.php/jutsi

Tabel 4. Pengujian Relay

\begin{tabular}{|c|c|c|}
\hline Tombol & Relay & Keterangan \\
\hline Klakson & 1 & Aktif \\
\hline Lampu ON & 2 & Aktif \\
\hline Lampu OFF & 2 & Non Aktif \\
\hline Atas & 3 & Aktif \\
\hline Bawah & 4 & Aktif \\
\hline
\end{tabular}

Sistem kendali dengan Arduino Uno menggunakan smartphone. Smartphone digunakan untuk mengendalikan motor listrik melalui relay dan memanfaatkan MIT App Inventor sebagai software untuk membangun sebuah aplikasi remote. Pengujian ini dilakukan bertujuan untuk mengetahui apakah nantinya mobil listrik berjalan sesuai dengan perintah yang dikirim dari aplikasi remote control. Berikut hasil pengujian dari smartphone dan relay:

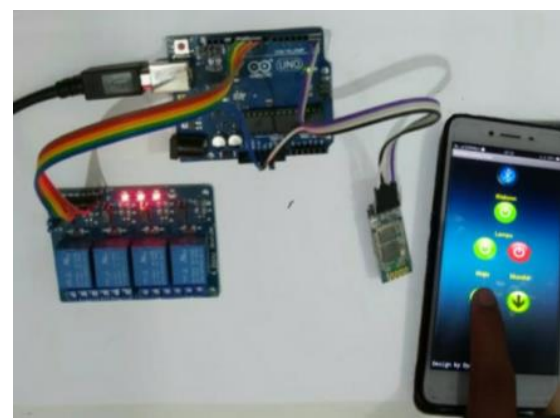

Gambar 7. Pengujian Aplikasi Remote Control berikut:

Adapun hasil pengujian dari aplikasi remote control terhadap relay yaitu sebagai

Tabel 5. Hasil Pengujian Aplikasi Remote Control

\begin{tabular}{|c|c|}
\hline Input Tombol & Reaksi Relay \\
\hline Klakson & Relay 1 ON \\
\hline Lampu ON & Relay 2 ON \\
\hline Lampu OFF & Relay 3 ON \\
\hline Atas & Relay 3 OFF \\
\hline Bawah & Relay 4 ON \\
\hline
\end{tabular}

Untuk pengujian motor listrik menggunakan sebuah baterai Aki sebagai sumber tegangan untuk menggerakkan motor, dan kemudian dihubungkan ke relay 3 dan relay 4 pada rangkaian alat. Adapun gambar motor listrik relay yang terhubung dengan relay pada rangkaian alat sebagai berikut: 
Vol. 1 No. 1, Feb 2021, hlm. 9 - 18

DOI: https://doi.org/10.33330/.v1i1.1008

Available online at http://jurnal.stmikroyal.ac.id/index.php/jutsi

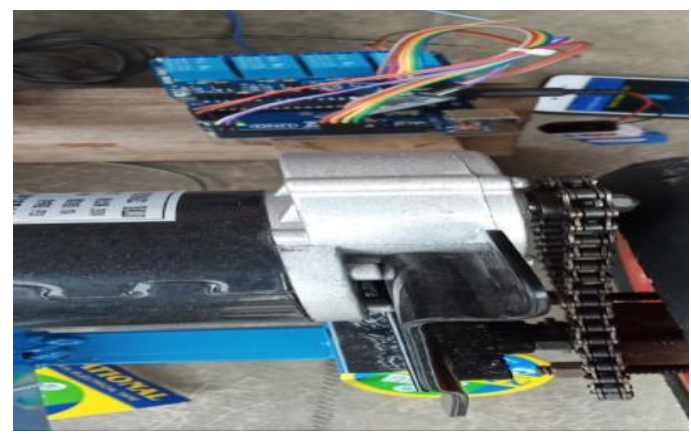

Gambar 8. Pengujian Motor DC

Adapun hasil pengujian dari aplikasi remote control terhadap relay yaitu sebagai berikut:

Tabel 6. Pengujian Motor DC

\begin{tabular}{|l|l|c|c|c|c|c|}
\hline \multirow{2}{*}{ Aksi } & \multirow{2}{*}{ Tombol } & \multicolumn{2}{|c|}{ Relay } & \multicolumn{2}{c|}{$\begin{array}{c}\text { Pin } \\
\text { Motor }\end{array}$} & Keterangan \\
\cline { 3 - 7 } & & 3 & 4 & A & B & \\
\hline Tekan & Maju & Aktif & - & 1 & 0 & $\begin{array}{c}\text { Motor } \\
\text { berputar ke } \\
\text { kanan } \\
\text { (Maju) }\end{array}$ \\
\hline Lepas & Maju & - & - & 0 & 0 & $\begin{array}{c}\text { Motor } \\
\text { berhenti }\end{array}$ \\
\hline Tekan & Mundur & & Aktif & 0 & 1 & $\begin{array}{c}\text { Motor } \\
\text { berputar ke } \\
\text { kiri } \\
\text { (Mundur) }\end{array}$ \\
\hline Lepas & Mundur & - & - & 0 & 0 & $\begin{array}{c}\text { Motor } \\
\text { berhenti }\end{array}$ \\
\hline
\end{tabular}

Dalam pengujian rangkaian keseluruhan, maka semua komponen dihubungkan dengan rangkaian alat. Dan kemudian dilakukan pengujian pengkoneksian Bluetooth dan pengujian tombol perintah pada aplikasi melalui smartphone. Adapun gambar rangkaian keseluruhan dan smartphone sebagai berikut:

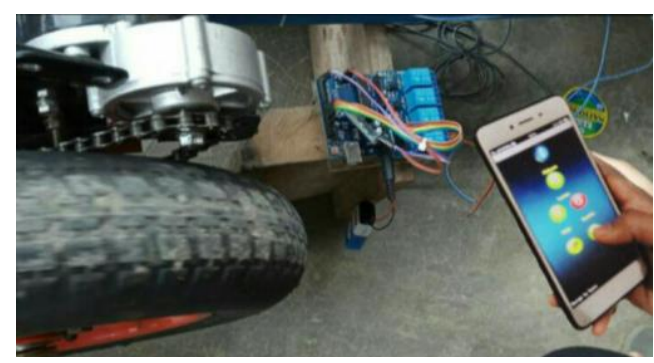

Gambar 9. Pengujian Rangkaian Keseluruhan

Setelah dilakukan pengujian sebanyak 2 kali dari rangkaian keseluruhan, berikut hasil pengujian dari rangkaian keseluruhan alat dan smartphone. 
Vol. 1 No. 1, Feb 2021, hlm. 9 - 18

DOI: https://doi.org/10.33330/.v1i1.1008

Available online at http://jurnal.stmikroyal.ac.id/index.php/jutsi

Tabel 7. Hasil Pengujian Alat Keseluruhan

\begin{tabular}{|l|l|l|l|l|}
\hline Aksi & Tombol & Jarak & $\begin{array}{l}\text { Reaksi } \\
\text { Relay }\end{array}$ & $\begin{array}{l}\text { Reaksi } \\
\text { Mobil } \\
\text { Listrik }\end{array}$ \\
\hline Tekan & Klakson & $\begin{array}{l} \pm 10 \\
\text { Meter }\end{array}$ & $\begin{array}{l}\text { Relay } \\
1 \text { ON }\end{array}$ & $\begin{array}{l}\text { Klakson } \\
\text { ON }\end{array}$ \\
\hline Lepas & Klakson & $\begin{array}{l} \pm 10 \\
\text { Meter }\end{array}$ & $\begin{array}{l}\text { Relay } \\
1 \text { OFF }\end{array}$ & $\begin{array}{l}\text { Klakson } \\
\text { OFF }\end{array}$ \\
\hline Tekan & $\begin{array}{l}\text { Lampu } \\
\text { ON }\end{array}$ & $\begin{array}{l} \pm 10 \\
\text { Meter }\end{array}$ & $\begin{array}{l}\text { Relay } \\
2 \text { ON }\end{array}$ & $\begin{array}{l}\text { Lampu } \\
\text { ON }\end{array}$ \\
\hline Tekan & $\begin{array}{l}\text { Lampu } \\
\text { OFF }\end{array}$ & $\begin{array}{l} \pm 10 \\
\text { Meter }\end{array}$ & $\begin{array}{l}\text { Relay } \\
2 \text { OFF }\end{array}$ & $\begin{array}{l}\text { Lampu } \\
\text { OFF }\end{array}$ \\
\hline Tekan & Atas & $\begin{array}{l} \pm 10 \\
\text { Meter }\end{array}$ & $\begin{array}{l}\text { Relay } \\
3 \text { ON }\end{array}$ & $\begin{array}{l}\text { Motor } \\
\text { maju }\end{array}$ \\
\hline Lepas & Atas & $\begin{array}{l} \pm 10 \\
\text { Meter }\end{array}$ & $\begin{array}{l}\text { Relay } \\
\text { 3 OFF }\end{array}$ & $\begin{array}{l}\text { Motor } \\
\text { Berhenti }\end{array}$ \\
\hline Tekan & Bawah & $\begin{array}{l} \pm 10 \\
\text { Meter }\end{array}$ & $\begin{array}{l}\text { Relay } \\
\text { 4 ON }\end{array}$ & $\begin{array}{l}\text { Motor } \\
\text { mundur }\end{array}$ \\
\hline Lepas & Bawah & $\begin{array}{l} \pm 10 \\
\text { Meter }\end{array}$ & $\begin{array}{l}\text { Relay } \\
\text { 4 OFF }\end{array}$ & $\begin{array}{l}\text { Motor } \\
\text { Berhenti }\end{array}$ \\
\hline
\end{tabular}

Prinsip kerja dari alat pengendali mobil listrik ini menggunakan aplikasi App Inventor pada Smartphone Android untuk klakson, lampu dan motor DC. Jika tombol klakson ditekan maka klakson akan menyala, jika dilepas maka klakson mati. Jika tombol lampu ON ditekan maka lampu mobil listrik akan menyala, dan jika tombol lampu OFF ditekan maka lampu mobil listrik akan mati. Kemudian jika tombol atas (Forward) ditekan maka mobil listrik akan bergerak maju, dan ketika tombol dilepas, maka mobil akan berhenti. Jika tombol bawah (Reverse) ditekan maka mobil listrik akan bergerak mundur dan ketika tombol dilepas, maka mobil akan berhenti. Penekanan setiap tombol pada aplikasi akan membersinyal output yang dapat terhubung ke Bluetooth HC-05. Program yang dibuat dan disimpan dalam IC Mikrokontroller akan mengontrol klakson, lampu, dan motor DC sesuai dengan masing-masing logika yang diberikan.

Untuk perancangan program dapat diikuti logika dari sistem yaitu : (1) Deteksi Bluetooth, Pada saat modul Bluetooth telah aktif, maka Bluetooth pada smartphone harus ON, kemudian dilakukan pengkoneksian setelah modul Bluetooth terdeteksi oleh smartphone., (2) Fungsi tombol, Setelah Bluetooth sudah terkoneksi maka tombol pada aplikasi sudah dapat berfungsi, setiap tombol yang ditekan akan memberikan reaksi terhadap mobil listrik, baik klakson, lampu maupun motor.

\section{SIMPULAN}

Setelah dilakukan perancangan, kemudian dilakukan pengujian dan penulis dapat menarik kesimpulan bahwa sesuai judul yang penulis ambil, pemanfaatan smartphone sebagai sistem kendali pada kendaraan bermotor sudah berhasil dan dapat digunakan, lampu dan klakson dapat menyala dan mati, mobil dapat bergerak maju dan mundur sesuai peritah yang diterima melalui tombol yang ada pada aplikasi di smartphone. Perancangan sistem kendali kendaraan bermotor jenis mobil listrik 
Vol. 1 No. 1, Feb 2021, hlm. 9 - 18

DOI: https://doi.org/10.33330/.v1i1.1008

Available online at http://jurnal.stmikroyal.ac.id/index.php/jutsi

menggunakan Mikrokontroler Arduino Uno sebagai pengendali dan pengolah data input yang diterima dari Smartphone melalui relay, sehingga dapat mengeluarkan data output berupa gerakan dari motor DC, klakson dan lampu mobil listrik.

\section{DAFTAR PUSTAKA}

[1] A. B. Lantemona and A. Patombongi, "Sistem Kendali Remote Kontrol Smartphone," J. Sist. Inf. Dan Tek. Komput., vol. 4, no. 1, pp. 19-24, 2019.

[2] I. Solikin, "Implementasi Penggunaan Smartphone Android untuk Control PC (Personal Computer)," J. Inform. J. Pengemb. IT, vol. 3, no. 2, pp. 249-252, 2018, doi: 10.30591/jpit.v3i2.766.

[3] N. Chayati, A. Haryoko, and A. Wijayanti, "Perancangan Mobil Robot Dengan Pengendali Suara Berbasis Android Dan Mikrokontroler Arduino," Peranc. Mob. Robot Dengan Pengendali Suara Berbas. Android Dan Mikrokontroler Arduino, no. September, 2018.

[4] Y. Suzantry H and Y. Mardiana, "Mobil Remote Control Berbasis Arduino Dengan Sistem Kendali Menggunakan Android," Pros. Semin. Ilmu Komput. dan Teknol. Informas, vol. 3, no. 1, 2018, [Online]. Available: http://ejournals.unmul.ac.id/index.php/SAKTI/article/view/2084/pdf.

[5] D. Setiawan, "Rancangbangun Robot Mobil Kontrol Sederhana Menggunakan Arduino Berbasis Android System," J. Sains, Teknol. dan Ind. UNILAK, vol. 14, no. 1, pp. 101-107, 2016.

[6] Sumardi, "PERANCANGAN SISTEM STARTER SEPEDA MOTOR MENGGUNAKAN APLIKASI ANDROID BERBASIS ARDUINO UNO Sumardi," J. Metik, Vol 1 No 1 2017, vol. 53, no. 9, pp. 1689-1699, 2019. 